\title{
High efficacy with deep nurse-administered propofol sedation for advanced gastroenterologic endoscopic procedures
}

Authors

Institutions
Jeppe Thue Jensen ${ }^{1}$, Pernille Hornslet ${ }^{1}$, Lars Konge ${ }^{2}$, Ann Merete Møller ${ }^{3}$, Peter Vilmann ${ }^{1}$

Gastro unit D, Department of endoscopy, Copenhagen University Hospital Herlev, Denmark

${ }^{2}$ Copenhagen Academy for Medical Education and Simulation, University of Copenhagen and the Capital Region of Denmark, Denmark

${ }^{3}$ Department of Anaesthesiology, Copenhagen University Hospital Herlev, Denmark

\section{Bibliography}

DOI http://dx.doi.org/

10.1055/s-0041-107899

Published online: 7.12.2015

Endoscopy International Open

2016; 04: E107-E111

(c) Georg Thieme Verlag KG

Stuttgart · New York

E-ISSN 2196-9736

\section{Corresponding author}

\section{Jeppe Thue Jensen}

Gastro unit D

Department of Endoscopy University Hospital Herlev, Gastroenheden D, Endoskopi Herlev Ringvej 75| 1735 Herlev Jeppe.thue.jensen.01@regionh. dk
Background and study aims: Whereas data on moderate nurse-administered propofol sedation (NAPS) efficacy and safety for standard endoscopy is abundant, few reports on the use of deep sedation by endoscopy nurses during advanced endoscopy, such as Endoscopic Retrograde Cholangiopancreatography (ERCP) and Endoscopic Ultrasound (EUS) are available and potential benefits or hazards remain unclear. The aims of this study were to investigate the efficacy of intermittent deep sedation with propofol for a large cohort of advanced endoscopies and to provide data on the safety.

Patients and methods: All available data from patients sedated with intermittent deep NAPS for ERCP, EUS or double balloon enteroscopy (DBE, since the method was implemented in May 2007 through December 2012 were included for evaluation in a retrospective case-control design.

\section{Introduction}

$\nabla$

Nurse-administered propofol sedation (NAPS) or non-anesthesiologist-administered propofol (NAAP) sedation is increasingly used for procedural sedation, particularly gastrointestinal endoscopy. Previously published large volume studies primarily evaluated the use of moderate NAPS for gastroscopies, sigmoidoscopies, and colonoscopies $[1,2]$. Evidence on NAPS efficacy and safety for advanced interventional endoscopy, such as endoscopic retrograde cholangiopancreatography (ERCP) and endoscopic ultrasound (EUS), is more limited $[3,4]$ and even more so when deep sedation is applied.

The increased focus on patient related quality and the development of advanced endoscopies such as ERCP, EUS, enteroscopies, and advanced colonoscopies has led to increased sedation requirements. The procedures are often longer than standard endoscopy and require a high degree of patient compliance in order to be successful [5].
Results: Data from 1899 patients undergoing 1899 procedures were included for evaluation. All but one procedure were completed with intermittent deep NAPS. The mean propofol dose was $397 \mathrm{mg}$ (SD: 232.4) and the infusion rate was $23.9 \mathrm{mg} / \mathrm{kg}$. The frequency of hypoxia was $4.3 \%$ and 20 patients needed assisted ventilation (1.1\%). Anesthesiologic support was requested eight times $(0.4 \%)$. One patient was intubated due to suspected aspiration.

Conclusions: Intermittent deep NAPS for advanced endoscopies in selected patients provided an almost $100 \%$ success rate. However, the rate of hypoxia, hypotension and respiratory support was high compared with previously published data, but the method was still assessed as safe.

Hence, either sedation or general anesthesia is almost always needed. The use of conscious sedation is sometimes insufficient during advanced endoscopy, especially upper endoscopy, and the use of deep sedation by non-anesthesia staff is debatable, particularly in the presence of considerable comorbidity $[6,7]$. Therefore, general anaesthesia is commonly applied. The use of intermittent deep sedation could lead to a larger proportion of successfully completed advanced endoscopies without the need for general anesthesia. Administration by non-anesthesia staff would reduce the procedure costs and sedation would shorten time to induction, time to discharge, and put less stress on the vital functions of the patient than general anesthesia. Deep sedation with midazolam, alone or in combination with an opioid is impractical. In a high-output unit, the prolonged discharge time after deep sedation is often unacceptable and the risk of re-sedation after antidote administration is increased. Furthermore, the 
clinical effect of midazolam has a high degree of interpersonal variation [8].

With a short, context-sensitive half-life of 2 to 4 minutes, propofol administration can provide for periods of deep sedation with no risk of re-sedation and fast readiness for discharge [9]. With the increased sedation requirements, adverse events occur more frequently during advanced endoscopy $[3,4]$ than during standard endoscopy $[10,12]$ and likely even more so during deep sedation. From a safety perspective, adverse events should be minor and self-resolving or successfully handled by the endoscopy team without health consequences for the patient and the efficacy should be high to render deep sedation beneficial as compared to conscious sedation or general anesthesia. The aims of this study were to analyze the efficacy and safety of intermittent deep sedation with propofol in a large cohort of advanced endoscopies.

\section{Patients and methods}

$\nabla$

Ethical approval was obtained from the Capital Region Ethics Committee No: H-4-2013-171 and the National Data protection agency No: HEH-2013-077. We used a retrospective casecontrol design, with cases being patients who developed an adverse event (dichotomous as 0 or 1 ) and the remainder serving as controls. All available data from patients sedated with NAPS for ERCP, EUS or double balloon enteroscopy (DBE) since the method was implemented in May 2007 through December 2012 were included for evaluation.

\section{Patients}

According to our guidelines, inclusion criteria for NAPS were age $\geq$ 16 years and ability to comply with 6 hours of fasting from solids and 2 hours of fasting from fluids. Patients were excluded if they were American Society of Anesthesiologists (ASA) class > 2 (ASA class 3 patients in a stable condition were allowed); had a body mass index $>35 \mathrm{~kg} / \mathrm{m}^{2}$; were allergic to soy, eggs, or peanuts; or had a history of complicated anaesthesia, potentially difficult airway (composite score of Mallampati score, atlanto-occipital movement, thyromental distance and dental status), ventricular retention, pregnancy, or sleep apnea. All patients undergoing emergency endoscopies were excluded.

\section{Training}

We have used a refract bolus propofol regimen in our unit since 2007. The guideline concept was originally developed by J. A. Walker (Medford, Oregon) and adapted to Danish standards. The endoscopist and nurse administering propofol complete $2 \frac{1}{2}$-day theoretical and practical course with full-scale simulation training in administration and the handling of adverse events. The course is completed with an exam and followed by bedside observation and supervised sedation (1 day for doctors, 4 weeks for nurses), gradually working more independently.

\section{Sedation}

Depth of sedation was assessed prior to introduction of the endoscope based on normal tone verbal stimulation, loss of ciliary reflexes, and loss of muscle tone. During the procedure, the depth and frequency of respiration served as the most important indicator of sedation depth. The sedation depth aimed for was a sleeping, unresponsive, and motionless patient with no gagging or coughing during introduction of the endoscope. This state was maintained throughout procedure, corresponding to deep sedation during endoscopic stimulation and moderate or deep sedation in the absence of stimulation. If a patient's cardiopulmonary status was unstable, as expressed by a depression in vital parameters, the sedation was lifted one level.

\section{Propofol administration}

Propofol was administered as intermittent bolus monotherapy by a dedicated endoscopy nurse, using the same guidelines as for standard endoscopies. Sufficient sedation for gag-free introduction of the endoscope was achieved with a dose of $100 \mathrm{mg}$ minus the patient's age in years, but no more than $60 \mathrm{mg}$ (hence, an 80 -year-old would receive $20 \mathrm{mg}$ ). Additional doses of half the initial dose could be administered every $45-60$ seconds until the patient was unresponsive to verbal and light tactile stimulation, as assessed by the team together. Maintenance of sedation was achieved with intermittent doses of $10-20 \mathrm{mg}$ if the patient showed signs of discomfort, sound or movement, or every 1 to 2 minutes if the patient was a sleep with stable cardiopulmonary status. The dedicated nurse continuously monitored the patient's vital parameters on the monitor and the depth and frequency of respiration by assessing movement of the thorax and the air flow over the nose and mouth in the palm of a hand.

\section{Adverse events}

All patients were monitored with pulse oximetry, blood pressure (BP) taken every five minutes, and electrocardiography. Saline infusion $(500 \mathrm{~mL} / \mathrm{hr})$ and supplemental oxygen $(3 \mathrm{~L} / \mathrm{min})$ flow on a nasal cannula were administered to all patients and initiated a minimum of 3 minutes prior to sedation. Adverse events were oxygen saturation $(\mathrm{SAT} \%)<92 \%$, measured with pulse oximetry or a drop in BP from baseline of more than $50 \mathrm{mmHg}$ systolic or $30 \%$ in mean arterial pressure (MAP). Furthermore, arrhythmia was registered. In near adverse events, temporary increases in saline infusion to $2 \mathrm{~L} / \mathrm{h}$ and oxygen flow to $5 \mathrm{~L} / \mathrm{min}$ were administered as a precaution. Handling of adverse events was recorded as a dichotomous outcome ( 0 or 1$)$ in case of administration of ephedrine 5-10 mg, airway manipulation (oral- or nasal airway and suction) and mask ventilation.

\section{Data items and statistical analysis}

Sedation was considered efficient when the procedure was completed, regardless of findings. Sedation was considered inefficient when the procedure was incomplete or disrupted due to pain, movement or a sedation-related adverse event. Other than adverse events and handling, baseline demographics recorded were recorded sex, age, ASA class, procedure type, duration of sedation (available for the last 1200 procedures), and total propofol dose. Unsuccessful procedures and procedures that required anesthesiologic assistance also were recorded.

Statistics were computed using IBM SPSS ${ }^{\mathrm{TM}}$ version 19. Binary logic regression was used to compare demographic risk factors and propofol administration in cases and controls. A $P$ value $<0.05$ was considered significant.

\section{Results \\ $\nabla$}

Data from 1899 patients undergoing 1899 procedures were included for evaluation. All but one procedure were completed with intermittent deep NAPS. One ERCP was disrupted and anesthesiologic expertise was summoned $(0.05 \%$ of total). The mean 
Table 1 Patient and procedure characteristics.

\begin{tabular}{|c|c|}
\hline & EUS, ERCP, DBE \\
\hline Patients, n & 1899 \\
\hline Age, $n$ & 1896 \\
\hline Mean (SD) & $62.5(15.7)$ \\
\hline Range (years) & $15-96$ \\
\hline Sex, n & 1899 \\
\hline M (\%) & $824(43.4)$ \\
\hline$F(\%)$ & $1075(56.6)$ \\
\hline ASA class, n & 1882 \\
\hline I (\%) & $455(24.0)$ \\
\hline II (\%) & $1158(61.0)$ \\
\hline III (\%) & $269(14.2)$ \\
\hline Unknown (\%) & $17(0.9)$ \\
\hline Total procedures & 1899 \\
\hline EUS (\%) & $1401(73.8)$ \\
\hline $\operatorname{ERCP}(\%)$ & $455(24.0)$ \\
\hline $\mathrm{DBE}(\%)$ & $43(2.3)$ \\
\hline \multicolumn{2}{|l|}{ Sedation } \\
\hline Propofol dose, $n$ & 1819 \\
\hline Mean (SD) & $397.0 \mathrm{mg}(232.4)$ \\
\hline Median & $340 \mathrm{mg}$ \\
\hline Sedation time, $\mathrm{n}$ & 1194 \\
\hline Mean (SD) & $27.9 \min (30.9)$ \\
\hline Median & $21.0 \mathrm{~min}$ \\
\hline Mg propofol/min, n & 1193 \\
\hline Mean (SD) & $23.9 \mathrm{mg} / \mathrm{min}(25.8)$ \\
\hline Median & $16.5 \mathrm{mg} / \mathrm{min}$ \\
\hline \multicolumn{2}{|l|}{ Adverse events } \\
\hline Hypoxia < $92 \%$ SAT & $81(4.3)$ \\
\hline Hypotension & $107(5.6)$ \\
\hline \multicolumn{2}{|l|}{ Handling } \\
\hline Assisted ventilation & $20(1.1)$ \\
\hline Airway manipulation & $86(4.5)$ \\
\hline Efedrin & $24(1.3)$ \\
\hline Anesthesiologic assistance & $8(0.4)$ \\
\hline
\end{tabular}

$\mathrm{N}$, patients with available data; SD, standard deviation; EUS, endoscopic ultrasound; ERCP, endoscopic retrograde cholangiopancreatography; DBE, double balloon enteroscopy

total propofol dose administered was $397 \mathrm{mg}$ with a mean infusion rate of $23.9 \mathrm{mg} / \mathrm{min}$ and the median procedure duration was 21 minutes. The rate of hypoxia was $4.5 \%$ with 20 patients needing assisted ventilation (1.1\%) and the rate of hypotension was $5.6 \%$, as shown in Table 1 . Anesthesiologic support was requested for 8 patients, 7 of whom were stabilized by the endoscopy team before the anesthesiologist arrived. The eight patient was intubated due to suspected aspiration after puncture of a pancreatic pseudocyst that contained $3 \mathrm{~L}$ of fluid. As shown in - Table2, the only demographic and procedure-related predictors of adverse events were age $(P<0.001)$ and total propofol dose $(P=0.007)$.

\section{Discussion}

The use of intermittent deep sedation provided a procedure success rate of nearly $100 \%$ in 1899 patients compliant with our NAPS criteria. However, intermittent deep sedation requires a relatively high propofol dose and leads to a higher frequency of sedation-related respiratory adverse events as compared with historical data, whereas the circulatory events rate seems less affected. Age and total propofol dose, but not ASA class, were associated with a higher frequency of adverse events.
The target state of motionless, unalert, and unaware were achieved for the full duration of all procedures and allowed for $99.95 \%$ of the procedures to be completed successfully, so the efficacy of sedation was good. The level of sedation was only registered prior to the procedure and before admission to the recovery room, but to avoid gagging, movement or cough, deep sedation is necessary for at least some part of EUS, DBE and ERCP and definitely achievable with a mean infusion rate of $23.9 \mathrm{mg} / \mathrm{min}$ propofol, hence the term "intermittent deep sedation." In a previously published study [13] of patients undergoing standard endoscopic procedures (sigmoidoscopy, colonoscopy, and esophagogastroduodenoscopy) who were sedated with the same regimen by the same nurses, the average propofol consumption was 331.6 $\mathrm{mg}$ and the infusion rate $20.9 \mathrm{mg} / \mathrm{min}$, both significantly lower than that required for advanced endoscopy. The higher propofol consumption during ERCP and EUS is confirmed by a number of authors reporting on mean propofol consumption between 78 mg and 277 mg during colonoscopy [9] as compared with $106-$ $388 \mathrm{mg}$ (Outlier low $51 \mathrm{mg}$ and high $519 \mathrm{mg}$ ) (397 mg in the current study) for an advanced endoscopic population [3] or studies targeting deep sedation during endoscopy [6,7,14-18]. Adding to the higher propofol dose, the patients were older and more were ASA class 3 as compared with patients undergoing standard endoscopy, and therefore likely to be more responsive to propofol $[13,19,20]$.

The screening of patients suited for intermittent deep sedation serves different purposes. A higher ASA classification and age are known to affect dose-response and assessment is necessary in order to adjust the propofol dose accordingly and thereby avoid an unpredictable course of sedation in patients with a possible reduced compensatory capacity $[19,20]$. As described in a previous study [21], airway management during advanced upper endoscopy, particularly ERCP but probably also EUS, is still a matter of discussion. Depending on culture and local setup, in-hospital patients are often intubated or sedated by anesthesia personnel and out-of-hospital patients are increasingly sedated by gastroenterologists. In this study, only fasting patients were included and only non-obese (BMI $\leq 35)$ patients with a low comorbidity (ASA 1,2, or stable class 3) were offered propofol. Causal analysis of the disrupted ERCP due to possible aspiration subsequently resulted in a review of the guideline so that pseudocyst drainage of a certain size required endotracheal intubation. The patient did not develop hypoxia or pneumonia. Furthermore, propofol was not given if patients presented a potentially difficult airway or difficult mask ventilation (DMV). Whereas the difficult airway is an exclusion criteria, screening for DMV is informally performed according to the OBESE criteria: Overweight (BMI $26 \mathrm{~kg} / \mathrm{m}^{2}$ ), Beard, Edentulous, Snoring, Elderly (age older than 55 years) [22]. Although not necessarily excluded, patients at risk are observed closely and preferably examined in the lateral recumbent position to avoid obstruction of airways. In a previous study [22], the incidence of DMV was $5 \%$ in a mixed population. Utilizing an airway screening strategy in this study, the percentage was evidently lower, and no DMV has been encountered. The theoretical risk of DMV could possibly be reduced even further if the "OBESE" guideline was used as an exclusion criterion. To conclude on procedure safety, the incidence and severity of adverse events, the handling capability and the consequence should be assessed simultaneously. With this guideline, treatment is initiated before SAT\% declines below $92 \%$. Only three patients experienced concomitant SAT\% $<88 \%$ and hypotension, all transient with a duration $<30$ seconds and resolved with airway 
Table 2 Adverse events.

\begin{tabular}{|c|c|c|c|c|c|c|c|}
\hline & No hypoxia & Hypoxia, n (\%) & $P$ value $^{1}$ & No hypotension & Hypotension (\%) & $P$ value $^{1}$ & $\begin{array}{l}\text { Overall } \\
P \text { value }^{2}\end{array}$ \\
\hline Patients, $\mathrm{n}$ & 1818 & $81(4.5)$ & & 1792 & $107(5.6)$ & & \\
\hline $\begin{array}{l}\text { Age, } n \\
\text { Mean (SD) }\end{array}$ & $\begin{array}{l}1815 \\
62.3(15.8)\end{array}$ & $\begin{array}{l}81 \\
66.4(11.9)\end{array}$ & 0.057 & $\begin{array}{l}1789 \\
62.2(15.8)\end{array}$ & $\begin{array}{l}107 \\
68.4(13.0)\end{array}$ & 0.001 & $<0.001$ \\
\hline $\begin{array}{l}\text { Sex } \\
M, n \\
F, n\end{array}$ & $\begin{array}{l}742 \\
1036\end{array}$ & $\begin{array}{l}42(5.1) \\
39(3.6)\end{array}$ & 0.078 & $\begin{array}{l}2543 \\
4093\end{array}$ & $\begin{array}{l}98(3.7) \\
106(2.5)\end{array}$ & 0.674 & 0.639 \\
\hline $\begin{array}{l}\text { ASA Class } \\
\mathrm{I}, \mathrm{n} \\
\mathrm{II}, \mathrm{n} \\
\mathrm{III}, \mathrm{n}\end{array}$ & $\begin{array}{l}441 \\
1101 \\
259\end{array}$ & $\begin{array}{l}14(3.1) \\
57(4.9) \\
10(3.7)\end{array}$ & 0.492 & $\begin{array}{l}2078 \\
4169 \\
360\end{array}$ & $\begin{array}{l}35(1.7) \\
135(3.1) \\
32(8.2)\end{array}$ & 0.809 & 0.826 \\
\hline Procedure total, $\mathrm{n}$ & 1818 & $81(4.5)$ & & 1792 & $107(5.6)$ & & \\
\hline $\begin{array}{l}\text { EUS, } \mathrm{n} \\
\text { ERCP, } \mathrm{n} \\
\text { DBE, } \mathrm{n}\end{array}$ & $\begin{array}{l}1336 \\
439 \\
43\end{array}$ & $\begin{array}{l}65(4.6) \\
16(3.5) \\
0(0)\end{array}$ & 0.379 & $\begin{array}{l}\frac{1319}{435} \\
38\end{array}$ & $\begin{array}{l}82(5.9) \\
20(4.4) \\
5(11.6)\end{array}$ & 0.263 & 0.141 \\
\hline Sedation & & & & & & & \\
\hline $\begin{array}{l}\text { Propofol dose, } n \\
\text { Mean (SD) }\end{array}$ & $\begin{array}{l}1742 \\
397.1(231.5)\end{array}$ & $\begin{array}{l}77 \\
394.5(252.6)\end{array}$ & 0.445 & $\begin{array}{l}1735 \\
394.7(231.0)\end{array}$ & $\begin{array}{l}84 \\
443.1(255.8)\end{array}$ & 0.009 & 0.007 \\
\hline $\begin{array}{l}\text { Sedation time, } \mathrm{n} \\
\text { Mean (SD) }\end{array}$ & $\begin{array}{l}1147 \\
27.8(31.0)\end{array}$ & $\begin{array}{l}47 \\
30.9(28.3)\end{array}$ & 0.935 & $\begin{array}{l}1162 \\
27.2(31.2)\end{array}$ & $\begin{array}{l}32 \\
27.2(18.1)\end{array}$ & 0.194 & 0.410 \\
\hline $\begin{array}{l}M g / m i n, n \\
\text { Mean (SD) }\end{array}$ & $\begin{array}{l}1146 \\
24.1(26.2)\end{array}$ & $\begin{array}{l}47 \\
17.0(11.1)\end{array}$ & 0.265 & $\begin{array}{l}1162 \\
23.8(26.0)\end{array}$ & $\begin{array}{l}31 \\
27.6(20.0)\end{array}$ & 0.085 & 0.145 \\
\hline
\end{tabular}

$\mathrm{n}$, patients with available data; SD, standard deviation.

${ }^{1}$ Logistic regression $P$ values

${ }^{2}$ Logistic regression $P$ values for hypoxia and hypotension combined

manipulation, increased oxygen and saline flow. None of these individuals required mask ventilation and no adverse event resulted in intubation or arrhythmia. In addition, all patients were expected to have some compensatory capacity. Mask ventilation were used in 20 cases to resolve hypoventilation regardless of saturation, and the frequency was significantly higher than during standard endoscopy (0.6\%) [13], aiming for the same depth of sedation, and higher than in all but one $(1.8 \%)$ of the previously reported studies on advanced endoscopy $(0-0.9 \%)$ [23]. The offensive mask ventilation strategy used in our unit could explain some of this difference. The threshold for anesthesiologic assistance was low and help was called as soon as anyone in the team felt uncertain about the course of events. Hence, seven of the calls were preventive and not yet associated with a serious adverse event, but the possible development of one.

Administering deep propofol sedation as refract bolus therapy is laborious due to the frequent administration (every $1-2 \mathrm{~min}$ ) and costly due to the extra nurse or physician required to administer propofol and monitor the patient. Recent research suggests that target-controlled infusion (TCI) could be a hands-free alternative to refract bolus administration. One study on deep sedation during standard endoscopy reported a frequency of hypoxia of $0 \%$ and a frequency of hypotension of $12 \%$ [18]. However, only $32 \%$ of patients were motionless during the entire procedure and $22 \%$ was reported to have moved severely. Movement can be acceptable, or even beneficial during colonoscopy repositioning, but less so during interventional endoscopy. One randomized controlled study of TCI for EUS reported good success with almost the same propofol dose as the current study and a low frequency of hypoxia (3\%) and no cases of assisted ventilation [24]. Manually controlled infusion (MCI) has also been suggested as a handsfree solution for advanced endoscopy and provides decent working conditions with a low rate of hypoxia $<90 \%(1 \%)$ [25] or good working conditions and similar rates of hypoxia ( $8 \%$ ) but a higher rate of hypotension (14\%) and prolonged recovery in the perfusor group vs. the refract bolus therapy group [14]. The refract bolus regimen used in this study was implemented due to the high degree of attention achieved with a dedicated nurse reassessing the patient before every bolus. Furthermore, endoscopy, particularly advanced endoscopy, is a dynamic process with passages requiring higher doses to maintain a motionless patient. Bolus therapy allows for a quick adaptation to these changes. It is, however, possible that TCI of propofol can provide for sedation deep enough to avoid infusion adjustments, as argued by one author [24].

This study has some limitations. The retrospective design increases the risk of selection bias and information bias. Furthermore, actual measurement of sedation depth in intervals would have been valuable. However, the tactile stimulation required to arouse a deeply sedated patient can be disturbing and arousal of a sleeping moderately sedated patient also seems unnecessary and therefore is not performed routinely. Furthermore, assessing sedation depth is subjective and interobserver-dependent and, therefore, prone to bias. The strength of this study is the large sample of advanced endoscopies, particularly EUS, which is why we believe that intermittent deep NAPS administered by trained personnel is highly useful and applicable for this cohort

\section{Conclusions}

$\nabla$

Intermittent deep NAPS for advanced endoscopic procedures in selected patients provided an almost $100 \%$ success rate, no patient discomfort, and required higher doses of propofol than previously reported, but was still safe. However, the rate of hypoxia and hypotension was high. Higher age and total propofol dose were predictors of adverse events.

Competing interests: Funding from Arvid Nilssons Fond 


\section{References}

1 Frieling T, Heise J, Kreysel C et al. Sedation-associated complications in endoscopy-prospective multicentre survey of 191142 patients. Z Gastroenterol 2013; 51: $568-572$

2 Rex DK, Deenadayalu VP, Eid E et al. Endoscopist-directed administration of propofol: a worldwide safety experience. Gastroenterology 2009; 137: 1229 - 1237

3 Goudra BG, Singh PM, Gouda G et al. Safety of non-anesthesia provideradministered propofol (NAAP) sedation in advanced gastrointestinal endoscopic procedures: comparative meta-analysis of pooled results. Dig Dis Sci 03. 03 2015: [Epub ahead of print]

4 Cheriyan DG, Byrne MF. Propofol use in endoscopic retrograde cholangiopancreatography and endoscopic ultrasound. World J Gastroenterol 2014; 18: $5171-5176$

5 Ootaki C, Stevens T, Vargo J et al. Does general anesthesia increase the diagnostic yield of endoscopic ultrasound-guided fine needle aspiration of pancreatic masses? Anesthesiology 2012; 117: 1044-1050

6 Nayar DS, Guthrie WG, Goodman A et al. Comparison of propofol deep sedation versus moderate sedation during endosonography. Dig Dis Sci 2010; 55: 2537-2544

7 Yarmus LB, Akulian JA, Gilbert C et al. Comparison of moderate versus deep sedation for endobronchial ultrasound transbronchial needle aspiration. Ann Am Thorac Soc 2013; 10: 121 - 126

8 Horn E, Nesbit SA. Pharmacology and pharmacokinetics of sedatives and analgesics. Gastrointest Endosc Clin N Am 2004; 14: 247-268

9 Dewitt J, McGreevy K, Sherman S et al. Nurse-administered propofol sedation compared with midazolam and meperidine for EUS: a prospective, randomized trial. Gastrointest Endosc 2008; 68: 499-509

10 Singh $H$, Poluha $W$, Cheang $M$ et al. Propofol for sedation during colonoscopy (Review). Cochrane Database Syst Rev 2008: 4

11 Rex DK, Heuss LT, Walker JA et al. Trained registered nurses/endoscopy teams can administer propofol safely for endoscopy. Gastroenterology 2005; 129: $1384-1391$

12 Kulling $D$, Orlandi $M$, Inauen $W$. Propofol sedation during endoscopic procedures: how much staff and monitoring are necessary? Gastrointest Endosc 2007; 66: 443 - 449

13 Jensen JT, Moeller AM, Hornslet $P$ et al. Moderate and deep nurse-administered propofol sedation is safe. Dan Med J 2015; 62: A5049 [Epup ahead of print]
14 Riphaus A, Geist C, Schrader K et al. Intermittent manually controlled versus continuous infusion of propofol for deep sedation during interventional endoscopy: a prospective randomized trial. Scand J Gastroenterol 2012; 47: 1078-1085

15 Amornyotin S, Leelakusolvong S, Chalayonnawin $W$ et al. Age-dependent safety analysis of propofol-based deep sedation for ERCP and EUS procedures at an endoscopy training center in a developing country. Clin Exp Gastroenterol 2012; 5: 123-128

16 Chun SY, Kim KO, Park DS et al. Safety and efficacy of deep sedation with propofol alone or combined with midazolam administrated by nonanesthesiologist for gastric endoscopic submucosal dissection. Gut Liver 2012; 6: 464-470

17 Lera Dos Santos ME, Maluf-Filho F, Chaves DM et al. Deep sedation during gastrointestinal endoscopy: propofol-fentanyl and midazolamfentanyl regimens. World J Gastroenterol 2013; 19: 3439-3446

18 Chan WH, Chang SL, Lin CS et al. Target-controlled infusion of propofol versus intermittent bolus of a sedative cocktail regimen in deep sedation for gastrointestinal endoscopy: Comparison of cardiovascular and respiratory parameters. J Dig Dis 2014; 15: 18 - 26

19 Scheepstra GL, Booij LH, Rutten CL et al. Propofol for induction and maintenance of anaesthesia: comparison between younger and older patients. Br J Anaesth 1989; 62: 54-60

20 Coley S, Mobley KA, Bone ME et al. Haemodynamic changes after induction of anaesthesia and tracheal intubation following propofol or thiopentone in patients of ASA grade I and III. Br J Anaesth 1989; 63: 423 428

21 Goudra B, Singh PM. ERCP: The Unresolved Question of Endotracheal Intubation. Dig Dis Sci 2014; 59: 513-519

22 Langeron 0 , Masso E, Huraux $C$ et al. Prediction of difficult mask ventilation. Anesthesiology 2000; 92: 1229-1236

23 Pagano N, Arosio M, Romeo F et al. Balanced Propofol Sedation in Patients Undergoing EUS-FNA: A Pilot Study to Assess Feasibility and Safety. Diagn Ther Endosc 2011: DOI 10.1155/2011/542159

24 Fanti L, Agostoni M, Arcidiacono PG et al. Target-controlled infusion during monitored anesthesia care in patients undergoing EUS: Propofol alone versus midazolam plus propofol A prospective double-blind randomised controlled trial. Digest Liver Dis 2007; 39: 81 - 86

25 Yusoff IF, Raymond G, Sahai AV. Endoscopist administered propofol for upper-GI EUS is safe and effective: a prospective study in 500 patients. Gastrointest Endosc 2004; 60: 356-360 